\title{
Generalized Peritonitis Caused by Spontaneous Intraperitoneal Rupture of the Urinary Bladder
}

\author{
Akinari TABARu, Masaaki Endou, Yoshifumi Miura and Makoto Otsuki
}

\begin{abstract}
We report a case of generalized peritonitis caused by spontaneous intraperitoneal rupture of the urinary bladder. A 74-year-old female was admitted with abdominal pain and biochemical findings of acute renal failure (ARF). She had recently complained of macrohematuria. She had a past history of radiotherapy for uterine cervical cancer and Parkinson's disease treated with levodopa and amantadine. We diagnosed this case as intraperitoneal rupture of the bladder by cystogram. Biochemical findings of ARF might have resulted from urine reabsorption. Intraperitoneal rupture of the bladder should be considered in all cases of peritonitis, especially in patients with urological symptoms and features of ARF.
\end{abstract}

(Internal Medicine 35: 880-882, 1996)

Key words: acute renal failure, radiotherapy, Parkinson's disease

\section{Introduction}

Spontaneous intraperitoneal rupture of the urinary bladder is an uncommon, but important, cause of generalized peritonitis. Most cases of spontaneous bladder rupture result from bladder wall lesions or outlet obstruction. Previously reported cases were diagnosed by cystography, contrast-enhanced computerized tomography (CT), cystoscopy and exploration. However, there are often difficulties in making the diagnosis. If diagnosis and treatment are delayed, the condition may be fatal. Here, we report a case of spontaneous bladder rupture with generalized peritonitis and biochemical findings of acute renal failure.

\section{Case Report}

A 74-year-old woman was admitted to our hospital as an emergency case on March 3, 1991, with the chief complaint of generalized abdominal pain and vomiting. She had suffered from gross hematuria since February 27, but without pyuria. Before that time, she had had no urological complaint and had urinated five to six times a day. Two days prior to admission, she gradually developed lower abdominal pain. Thereafter, her abdominal pain became generalized with vomiting. On the day of admission she had not voided any urine. She denied any abdominal trauma or alcohol intake. She had a previous history of cancer of the uterine cervix (stage IIIb) and of Parkinson's disease. Her uterine cervical cancer had been treated with external pelvic and intracavitary irradiation, $80.8 \mathrm{~Gy}$ as a total dose, in 1980. Three years after radiation therapy she compalined of melena and was diagnosed as radiation proctitis by romanoscopy. Her Parkinson's disease had been treated with levodopa $\left(\right.$ Madopar $\left.^{\circledR}\right)$ and amantadine $\left(\right.$ Symmetrel $\left.^{\circledR}\right)$ for about 10 years.

On admission, abdomen was markedly distended due to ascites and intestinal gas. She complained of severe tenderness of the whole abdomen without significant muscular defense and rebound tenderness. Bowel sounds were absent. The bladder was catheterized and about $80 \mathrm{ml}$ of bloody urine was obtained. Urinary volume for 10 hours was $450 \mathrm{ml}$. However, when irrigation was attempted, there was no return.

Laboratory data on admission are shown in Table 1. Many white blood cells and red blood cells were seen in the urinary sediment. Blood test showed marked leukocytosis with positive acute inflammatory reactions and revealed the feature of acute renal failure. Abdominal X-ray films showed multiple air-fluid levels, but no free air. Abdominal ultrasonography (US) and CT scan showed massive ascites, bilateral hydronephrosis and an enlarged bladder with urine retention (Fig. 1). Since these data suggest acute post-renal renal failure, cystoscopy and cystography were performed to identify the cause. Cystoscopic examination revealed edematous cystic mucosa with ulcer and trabeculation, but failed to reveal any points of perforation of the bladder wall. Cystogram showed massive intraperitoneal extravasation of contrast media (Fig. 2). We diagnosed the patient

From the Third Department of Internal Medicine, University of Occupational and Environmental Health, School of Medicine, Kitakyushu Received for publication April 12, 1996; Accepted for publication August 12, 1996

Reprint requests should be addressed to Dr. Makoto Otsuki, the Third Department of Internal Medicine, University of Occupational and Environmental Health, School of Medicine, 1-1 Iseigaoka, Yahatanisi-ku, Kitakyushu 807 
Table 1. Laboratory Findings on Admission

\begin{tabular}{|c|c|c|c|}
\hline \multirow{2}{*}{$\begin{array}{l}\text { Peripheral blood } \\
\text { White blood cells }\end{array}$} & \multicolumn{3}{|c|}{ Blood chemistry } \\
\hline & $20,200 / \mu 1$ & Total protein & $5.5 \mathrm{~g} / \mathrm{dl}$ \\
\hline Segmented neutrophi & ails $\quad 86 \%$ & Albumin & $3.3 \mathrm{~g} / \mathrm{dl}$ \\
\hline Lymphocytes & $6 \%$ & Blood urea nitrogen & $162 \mathrm{mg} / \mathrm{dl}$ \\
\hline Monocytes & $8 \%$ & Creatinine & $10.0 \mathrm{mg} / \mathrm{dl}$ \\
\hline Red blood cells & $450 \times 10^{4} / \mu 1$ & $\mathrm{Na}$ & $135 \mathrm{mEq} / \mathrm{l}$ \\
\hline Hemoglobin & $14.4 \mathrm{~g} / \mathrm{dl}$ & $\mathrm{K}$ & $5.4 \mathrm{mEq} / \mathrm{l}$ \\
\hline Hematocrit & $42.1 \%$ & $\mathrm{Cl}$ & $94 \mathrm{mEq} / \mathrm{l}$ \\
\hline Urinalysis & & $\mathrm{Ca}$ & $8.9 \mathrm{mg} / \mathrm{dl}$ \\
\hline Protein & $(3+)$ & Uric acid & $15.1 \mathrm{mg} / \mathrm{dl}$ \\
\hline Occult blood & $(3+)$ & \multicolumn{2}{|c|}{ Erythrocyte sedimentation rate } \\
\hline \multicolumn{2}{|c|}{ Urinary sediment } & \multicolumn{2}{|c|}{$103 \mathrm{~mm} / \mathrm{h}$} \\
\hline \multicolumn{2}{|c|}{$\begin{array}{l}\text { White blood cells } \\
\text { many / high-power field }\end{array}$} & \multirow[t]{2}{*}{ C-reactive protein } & \multirow[t]{2}{*}{$(6+<)$} \\
\hline $\begin{array}{l}\text { Red blood cells } \\
\text { many / high- }\end{array}$ & -power field & & \\
\hline
\end{tabular}

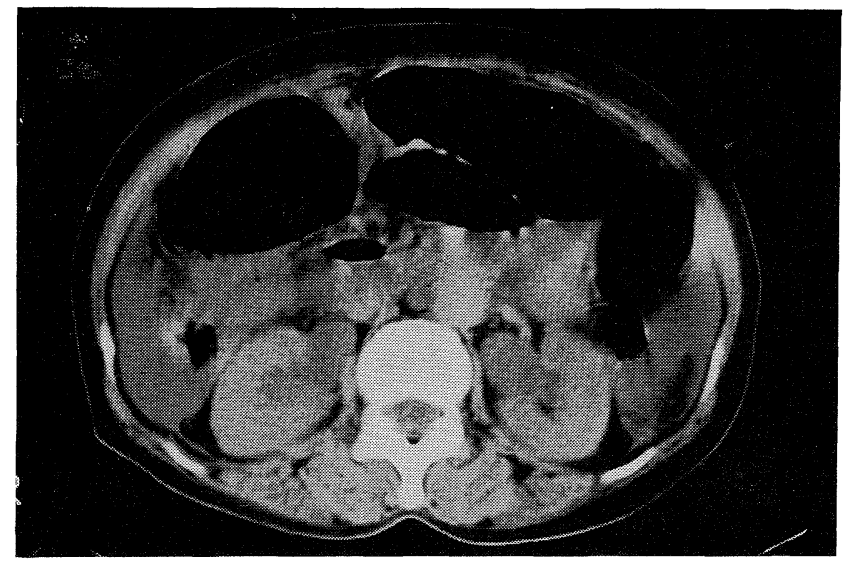

A

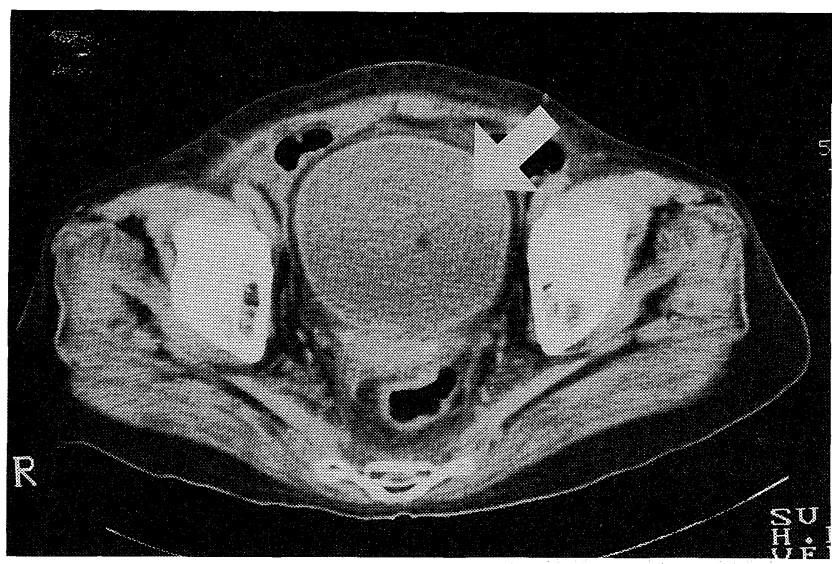

B

Figure 1. (A) CT of upper abdomen showing ascites and bilateral hydronephrosis. Increased gas in the intestine is shown. (B) CT of pelvis showing the enlarged bladder with retention of urine (arrow).

as peritonitis with paralytic ileus due to spontaneous intraperitoneal rupture of the urinary bladder and thus performed surgical treatment.

At laparotomy, a moderate amount of yellow fluid with pus in the peritoneal cavity and diffuse peritonitis was found. There were some huge coagulates in the bladder. A perforated pore, 8 $\mathrm{mm}$ in diameter, was discovered at the left-posterior wall of the bladder and was repaired after debridment. There was no recurrence of uterine cervical cancer and no diverticulum of the bladder. Histologically, acute and chronic cystitis with focal abscess formation in the muscle layer was seen. Pathological changes due to irradiation could not be found. Three days after operation, serum blood urea nitrogen and creatinine levels were normalized but leukocytosis and abnormalities of urinary sediment were continued for several days. Signs of paralytic ileus due to peritonitis disappeared and she was discharged from our hospital on March 28.

\section{Discussion}

Major causes of generalized peritonitis are appendicitis, perforations associated with diverticulitis, peptic ulcers, gangrenous gallbladder, and gangrenous obstruction of the small bowel from adhesive bands, incarcerated hernia, or volvulus (1). Spontaneous rupture of the urinary bladder is an uncommon cause of generalized peritonitis but a surgical emergency which may be rapidly fatal if its diagnosis and treatment are delayed or missed.

In most cases of spontaneous bladder rupture, an underlying pathology has been implicated. Bastable et al (2) reported in a 


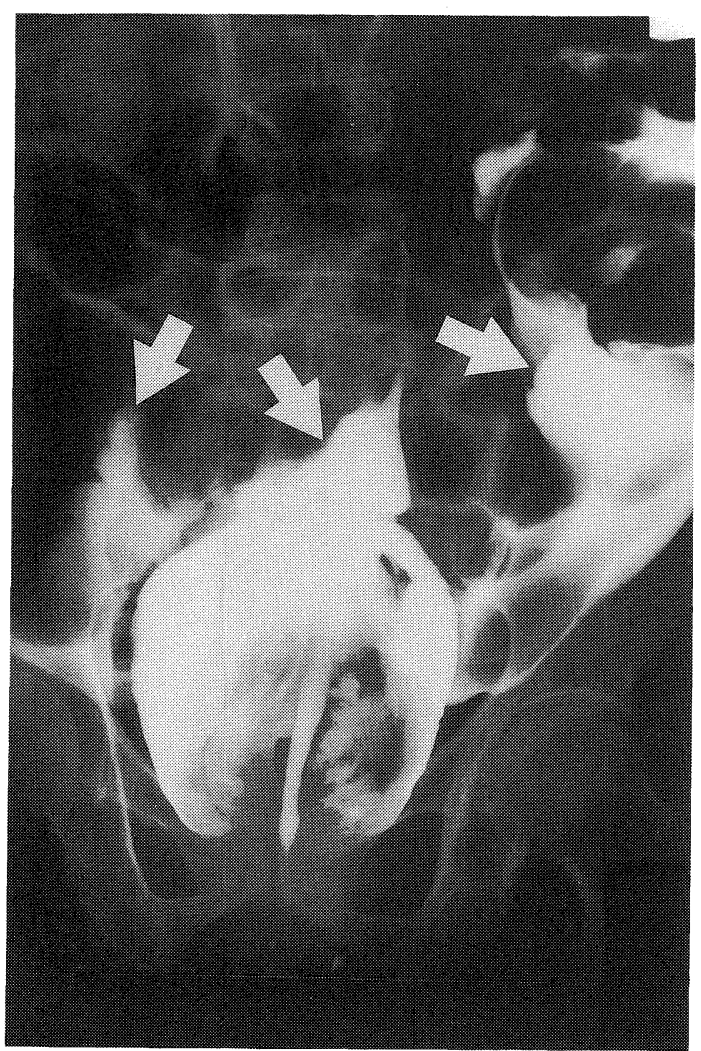

Figure 2. Cystogram demonstrating intraperitoneal leakage of the contrast media (arrows). Filling defects in the bladder are due to coagulated blood.

review of 66 patients that $28(42.4 \%)$ patients had a diseased bladder while $23(34.8 \%)$ had urinary retention due to either a neurogenic bladder or obstruction. Major pathologies of the bladder wall include chronic cystitis, tuberculosis and carcinoma $(2,3)$. Pathological changes after irradiation of the bladder region have also been reported to lead to rupture (4). In the present case, the bladder wall might have been weakened by the irradiation for uterine cervical cancer. Under this condition, severe cystitis with the obstruction of urethra by coagulated blood and voiding disturbance due to medication for Parkinson's disease might have induced perforation in the weakened part of the bladder wall.

When intraperitoneal rupture of the bladder occurs, a patient may complain of abdominal pain associated with muscular defense and muscle rigidity due to peritonitis, abdominal fullness and difficulty in voiding urine. A discrepancy in irrigation and withdrawal of a measured amount of saline through the urethral catheter may suggest the diagnosis. Any delay in diagnosis results in significant reabsorption of urea and creatinine through the peritoneum causing a significant elevation in blood urea and creatinine levels (5). In addition, the serum level of potassium increases, and sodium and chloride concentrations decrease. Because of the similarity in laboratory data, it is hard to distinguish intraperitoneal rupture of the urinary bladder from acute renal failure (6).

To obtain the diagnosis of bladder rupture, cystography is the most sensitive and accurate technique (7). As for other diagnostic methods, the usefulness of CT images using contrast media or ultrasonography with the instillation of saline and air has been reported (8-10). However achieving an accurate diagnosis has still proved to be difficult. Mokoena and Naidu (11) reported that there was a mean delay of 5.4 days (range 2 hours to 36 days) between an identifiable associated incident or the first medical attendance and diagnosis. In the present case, ultrasonography, CT and cystoscopy were not sufficient to establish a diagnosis of bladder rupture. Because there were urological symptoms and the features of acute renal failure with bilateral hydronephrosis, we further performed cystography which revealed the extravasation of contrast media into the peritoneal cavity. Based on these findings, we diagnosed our patient as suffering from intraperitoneal rupture of the bladder.

In conclusion, the most important key to early and accurate diagnosis of bladder rupture is to suspect this disorder in cases with peritonitis, especially in patients with urological symptoms and the features of acute renal failure.

\section{References}

1) Isselbacher KJ, La Mont JT. Disease of the peritoneum and mesentery. in: Harrison's Principles of Internal Medicine, Ed 11, Braunwald E, Isselbacher KJ, Petersdorf RG, Wilson JD, Maritin JB, Fauci AS, Eds. McGraw-Hill Book Company, New York, 1987, p.1306.

2) Bastable JRG, De Jode LR, Warren RP. Spontaneous rupture of the bladder. Br J Urol 31: 78, 1959.

3) Shaked A, Meretyk S, Pode D, Caine M. Non-traumatic spontaneous rupture of the urinary bladder. Can J Surg 29: 107, 1986.

4) Hansen HJ, Eldrup J. Spontaneous rupture of the urinary bladder - A late complication to radiotherapy. Case report. Scand J Urol Nephrol 23: 309 , 1989.

5) Heyns CF, Rimington PD. Intraperitoneal rupture of the bladder causing the biochemical features of renal failure. Br J Urol 60: 217, 1987.

6) Davenport A, Goldsmith HJ. Ruptured bladder presenting as acute renal failure. Br J Hosp Med 41: 579, 1989.

7) Carroll PR, McAninch JW. Major bladder trauma: the accuracy of cystography. J Urol 130: 887, 1983.

8) Horstman WG, McClennan BL, Heiken JP. Comparison of computed tomography and conventional cystography for detection of traumatic bladder rupture. Urol Radiol 12: 188, 1991.

9) Sivit CJ, Cutting JP, Eichelberger MR. CT diagnosis and localization of rupture of the bladder in children with blunt abdominal trauma: significance of contrast material extravasation in the pelvis. AJR Am J Roentgenol 164: 1243, 1995.

10) Itoh N, Kounami T. Spontaneous rupture of a bladder diverticulum: ultrasonographic diagnosis. J Urol 152: 1206, 1994.

11) Mokoena T, Naidu AG. Diagnostic difficulties in patients with a ruptured bladder. Br J Surg 82: 69, 1995. 